\title{
Environmental analysis of health damages coming from a residential neighborhood built in 150 countries
}

\author{
Modeste Kameni Nematchoua ${ }^{1,2,3} \cdot$ Somayeh Asadi $^{3} \cdot$ Esther Obonyo $^{4} \cdot$ Sigrid Reiter $^{2}$
}

Received: 31 October 2020 / Accepted: 1 November 2021

(C) The Author(s), under exclusive licence to Springer Nature B.V. 2021

\begin{abstract}
Decisions made in the design of urban developments at the neighbourhood scale influence damages on human health, which depend on location. So far, no standard has proposed the range of health damage coming from neighborhoods located in any region, due to the different morphologies of neighborhoods, and limited study numbers. Aware of this fact, this study was conducted with the aim to evaluate and to compare the effect of health damage produced by a sustainable neighborhood in which the same morphology was designed in several regions. To perform this comparison, the same neighborhood design is applied to 150 countries, but four parameters are adapted to each country: energy mix, local climate, building materials, and occupants 'mobility. In addition, this study analysis the induced health impact of the neighborhood over a life cycle of 100 years and examines the impact of mobility and renewable energy on the health, which was evaluated by Pleiades ACV software. Among the four local parameters (energy mix, local materials, climate, and transport), the energy mix has the most significant effect on the health damage. The results show that the countries having a lower concentration of renewable energy sources have higher health damage than others. Africa is the continent that most affected by health damage due to lack of having an eco-neighborhood. The building materials and electricity use are the main sources of health damage in a neighborhood. The implementation of photovoltaic panels on the roofs of an eco-neighborhood has a significant impact on the potential health damages. Among the different stages of the neighborhood life cycle, the operation stage is the most significant which is responsible over $50 \%$ of total health damage. It is important to multiply ecological neighborhoods around the world, because health damage is estimated to be $20 \%$ lower in sustainable neighborhoods than more conventional neighborhoods.
\end{abstract}

Keywords Health impact · LCA · Eco-neighborhood · Building materials · Eco-mobility · Eco-life style

Modeste Kameni Nematchoua

kameni.modeste@yahoo.fr

Extended author information available on the last page of the article 


\section{Introduction}

The environment destruction has a direct impact on human health. The quality of the air we breathe, the objects we use, and our daily activity are all factors that influence our health either positively or negatively. They affect human body through its respiratory tract, its digestive system, its skin, and its sense organs. The vast majority of people spend most of their lives locked up in their homes or work-places (Sergio Altomonte et al., 2020; Nematchoua et al., 2017a). Health damage caused by building is common and varies from one building to another (Nematchoua et al., 2019b). It is no longer a great surprise to note that the risks associated with these diseases vary considerably from one environment to another, from one geographic region to another (Gaurisankar \& Tanya, 2008). These geographical alternations show that there is a strong link with the environmental condition.

Historically, habitat and health have been two key concerns for every human being. Nowadays, the health security of buildings is becoming a public health issue. Indeed, in the past, the use of chemicals or contaminants was mainly reserved for the industrial world (Nematchoua et al., 2017a). Today, these products are everywhere, and especially in our homes as products of everyday use for building materials, maintenance, hygiene, etc. (Nematchoua et al., 2017b, 2017c; WHO, 2009). In the literature, the researches on the living environment and health have not yet produced a complete relationship between building environment and its impact on our well-being (Pinter-Wollman et al., 2018). It is imperative to use more concrete measures to reduce the health impacts of buildings. Indeed, renovation is considered as one of the methods to design healthy buildings (Nematchoua et al., 2017b, 2019b) on the other side, the impacts of poor housing on health are multiple and of varying intensities (e.g. Pathologies, disabilities, syndromes or disorders) in terms of physical or mental health as well as the well-being (HCSP, 2009). Sustainable neighborhoods are distinguished from other types of neighborhoods by the strict selection of building materials, ecology, friendliness and comfort, quality and economy (Maliene \& Malys, 2009).

Currently, several European countries are trying to develop an approach to study health damage in neighborhoods. The methodology varies, depending on national traditions, the political context, organizational models of the health system and social services, the actors and the institutions responsible for implementing them. Some studies analyzed health damage in a neighborhood. For example, Nematchoua et al. (2017a) explained that one of the fundamental principles of sustainable development is to design environments or neighborhoods that are healthy and have a low environmental impact. By analyzing several studies Moore et al. (2018) found that there is a direct relationship between health damage and types of construction. Liu et al. (2018) suggested that good neighborhood-level health policy can reduce the level of violence and poverty in the population. Mujahid and Roux (2010) showed that the neighborhood environment has an important action on the cardio-metabolic health of humans, especially women, while Staff et al. (2016) showed that women's cardio-metabolic rate varied according to their place of residence. Other studies focused on health and built environment (Galin et al., 2016; Headen et al., 2018; Janevic et al., 2010; Kelly, 2019; Messer et al., 2006; Laraia et al., 2007; O'Brien et al., 2017; US Census, 2019), but, conducting an accurate comparison and identifying influential parameters require to define a unique functional unit (e.g. same floor area of dwelling and tertiary buildings, same life span etc.).

Different methods including statistical and simulation models make it necessary to draw up the environmental impacts of a building (Carr et al., 2010; Foster \& Giles-Corti, 2008; 
Messer et al., 2012; Ncube et al., 2016; Peuportier, 2015; Zhang et al., 2015). At the scale of the building and the neighborhood, the method of the LCA was even standardized in several countries in European Union (Briggs et al., 2010; Simonen, 2014; Winkleby et al., 2006). It is currently the main scientifically sound approach to evaluate some environmental impacts at the scale of a neighborhood. Any potential consequence on the natural environment, human health and the depletion of natural resources were considered as an environmental impact (Gervasio et al., 2014). Thus, LCA is a process that produces the establishment of several means to identify environmental impacts (Popovici \& Peuportier, 2004; Simonen, 2014). Yet, it is very difficult to compare various environmental impacts resulting from the different stages of building construction. For instance, an LCA study was conducted in Canada and it was found that the Canadian health system generates 33 million tons of carbon dioxide equivalent $\left(\mathrm{CO}_{2}\right)$, or $4.6 \%$ of the national global, resulting in health damage of 4500 to 610,000 DALYS (Disability Adjusted Life Year) each year (Eckelman et al., 2018).

In this study, we specifically focused on health damage. Some studies focused on the LCA of health damage associated with buildings (Simonen, 2014). It is seen that all these studies mainly focus on the issues of one country/region indicating their local impact. However, it is needed to scale up these studies and focus on the world scale and investigate the global impacts. Problems related to human health should be solved on an international scale. Every country should feel concerned and be aware of the current environmental damages, as well as the necessity and the urgency to find solutions together. In this study, we pushed thinking further and conducted an LCA of an eco-neighborhood located in 150 countries to quantify, analysis, and compare health damage associated with it in a way that each case study has different climates, energy mix, construction materials and mobility behaviors. Unlike previous studies that only focus on a single life cycle stage (for example, renovation or use), we evaluated all four stages of building life including construction, use, renovation, and demolition.

\section{Methodology}

In this study, at the first step we carried out the environmental study of a sustainable neighborhood located in Belgium over 100 years, then, we adopted the same design in 149 other countries, while adapting four parameters specific to each country: energy mix, local climate, building construction materials, and occupants' mobility. Overall, in this study we have four steps: (a) site design; (b) LCA of the selected neighborhood; (c) modeling the same neighborhood in 149 other countries and conduct LCA; and (d) application of one scenario related to a greener environment, to reduce health damage (Nematchoua, 2020). The methodology carried out in this research includes the selection of the study place, inventory of environment data, studied environmental indicators, and the LCA tools. In this section, we have introduced methodology, in the next sub-section, we will describe this residential neighborhood.

\subsection{Neighborhood}

This neighborhood is initially located in Liege city in Belgium, and the same design is adapted in 149 countries representing the whole world. Some descriptions regarding this 
neighborhood was gave by Nematchoua and Reiter (2019). A view of this neighborhood is showed on Fig. 1.

This studied neighborhood showed the majority of criteria of a sustainable neighborhood, regarding the references published by some international organizations (Teller et al., 2014; Riera Pérez \& Rey, 2013).

In this work, alone the neighborhood residential part was investigated. In the LCA software, the site was represented by a functional unit "residential eco-district of 3.5 hectares (ha)comprising 1 ha of roads, driveways and parking lots, $17,800 \mathrm{~m}^{2}$ of green space, $19,740 \mathrm{~m}^{2}$ of floor space, housing around 219 people, studied on a life cycle of 100 years" (Nematchoua, 2020). Given the construction standards in Belgium compared to those of other countries, it is clear that Belgian buildings would hardly exist in Asian cities, the Middle East, Africa, and South America. For this, firstly, we have made a sensitivity study. Thus, in this study, we take into account country-specific standards for the choice of local materials. In the literature, it is seen that, the density of living space per person is very specific to each country, the inhabitants of Asian countries occupying very little space and the inhabitants of North America and Australia occupying very large spaces per person (Nematchoua, 2020). To remedy this problem, in this study, in the case of developed countries in Europe, North America, some Asian countries and Australia, we maintained 219 occupants in all the neighborhood, while in the case of others Asian country, Middle East, Africa, South America, we have fixed $438(219 * 2)$ occupants (this technique allowed us to reduce the space occupied per person in these countries) (Nematchoua, 2020). The next sub-section gives some information regarding energy mix and building materials applied in this study.

\subsection{Modelling of neighborhood}

The same eco-neighborhood is designed and simulated in 150 capitals located in 150 countries (Nematchoua, 2020). The choice of the capital, for representing each country was not random. Indeed, in most of these countries, the capital was considered as the most populated region of the country, with the highest pollution rate and health damage

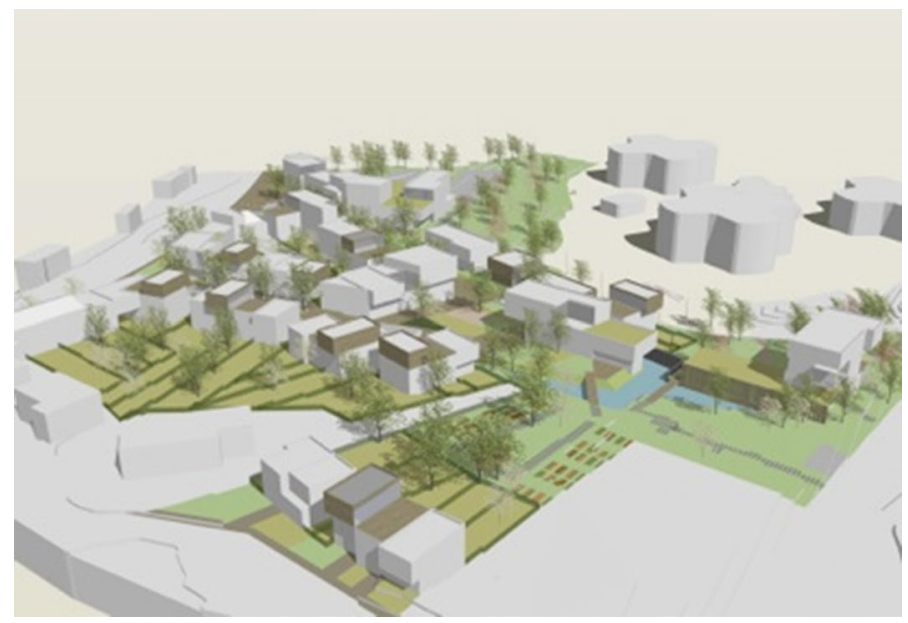

Fig. 1 The studied eco- neighborhood, near the University of Liège, in Belgium (Riera Pérez \& Rey, 2013) 
(Nematchoua, 2020). This strong population concentration has a significant influence on the environmental impacts, including health impact. According to the list established by the UN (United Nations), the day after June 28th, 2018, the number of countries in the world is 194. This study is applied in 150 countries chosen from the 194 known countries. Only 49 countries (in white in Fig. 3) have not been selected. example: Mayotte, Comoros, La Reunion, Seychelles, Mauritius, Guatemala, Cape Verde, Grenada, Guinea-Bissau, Kosovo, Macedonia, San Marino, Serbia ... We have excluded these countries because we did not have complete all the information relating to the electrical mix of these countries. We simultaneously applied four parameters for adapting this neighborhood in each country: the energy mix, local climate, building materials and occupants' mobility of each country (Nematchoua, 2020).

The information on the energy mix comes from the International Energy Agency (IEA) (IES, 2016) and the Energy Information System of each country. On the Pleiades ACV software, it was possible to freely select the different energy components mix (in \%) such as nuclear, fuel, coal, gas and renewable energy; then, assigning their corresponding values (Nematchoua, 2020).

The information on the local climate of each country was evaluated with the most recent Meteonorm software version (Remund et al., 2017).

The information on the construction materials was evaluated on the basis of 2018-2020 standards of each country, but also from information issued from the UN-habitat and some literature reviews (in particular for some African and Asian countries that do not have recent building standards). Regarding inhabitant mobility, the data was freely selected on Pleiades software which are standard and proposed by the simulation software when the location is selected (Nematchoua, 2020). These data are presented as follow: the type of site is a suburban site; the rate of occupants commuting daily is $80 \%$ in developed countries (USA, Japan, Germany, France, UK, etc.) and 50\% in developing countries (Cameroon, Madagascar, Haiti, Thailand, etc.). The distance of the weekly commute between home and shops $(1000 \mathrm{~m})$; distance from the public transport network $(500 \mathrm{~m})$, distance from the daily commute to work $5000 \mathrm{~m}$ (in developing countries) and 10,000 m (in developed countries). Presence of bike path: yes (only developed countries); public transportation: bus, subway, and tram. The description of database is given in the next section.

\subsection{Database and indicators}

The environmental data used come from the ECOINVENT database developed by different research institutes based in Switzerland (Nematchoua et al., 2019d). Life cycle inventory (LCI) analysis is defined by ISO as the 'phase of life cycle assessment involving the compilation and quantification of inputs and outputs for a product throughout its life cycle'. The inventory relates to the compilation of various environmental inputs and outputs involved in the life cycle of a product.

The data include, for each process and material, a life cycle inventory that contains all material and energy flows into and out of the system (Peuportier et al., 2006): (i) resources consumed (energy water, etc.); (ii) emissions in the different natural environments: air, water or soils (ammonia in water, metals in the soil, $\mathrm{CO}_{2}$, etc.); (iii) waste created (inert, toxic or radioactive). We used version 2.2 of the ECOINVENT database. The development of this database follows processes that have been verified several times to make sure they are reliable and the contents of this database have been verified and validated by international experts. The ECOINVENT Centre is known to be, one of an international leader in 
environmental database. In this study, we concentrated on one (01) environmental impact: Damage to human health (via the Disability Adjusted Life Year, DALYs) (Goedkoop \& Spriemsma, 2001). In this section, we have given some indicators, in the next section, we will describe the tools used in this research.

One DALY represents the loss of the equivalent of one year of full health. DALYs for a disease or health condition are the sum of the years of life lost to due to premature mortality (YLLs) and the years lived with a disability (YLDs) due to prevalent cases of the disease or health condition in a population (WHO, 2012). DALYs for a specific cause are calculated as the sum of the years of life lost due to premature mortality (YLLs) from that cause and the years of years of healthy life lost due to disability (YLDs) for people living in states of less than good health resulting from the specific cause. The YLLs for a cause are calculated as the number of cause-specific deaths multiplied by a loss function specifying the years lost for deaths as a function of the age at which death occurs (WHO, 2012).

\subsection{Simulation tool}

In this study, we used a combination of all the new IZUBA energy software. Indeed, the interface of the most recent version (Pleiades software, version 4.19.1.0), is divided into 6 modules: Library, Modeler (called ALCYONE for the old software version), BIM, Editor (called COMFIE-PLEIADES), Results and ACV (nova-EQUER) (Nematchoua, 2020). It is notice that each one has a precise role. Indeed, all these tools were regularly used by several experts of LCA field (Salomon et al., 2005; Rossi et al., 2012a; Rossi et al., 2012b; Nematchoua et al., 2019c; Nematchoua and Reiter 2019).

Different details regarding these simulation tools are given by Nematchoua et al. (2019c) and Nematchoua and Reiter (2019). This neighborhood was regrouped in 10 blocks with heating requirements showed in Table 1.

The original building and neighborhood data come from the Pleiades through a thermal/ACV coupling allowing to automatically recovering all the characteristics of the building: data on the structure of the building and the elements involved in thermal calculations, energy consumption, etc. These data are then supplemented with specific LCA data, for example, all elements that are not part of the thermal study including general and

Table 1 Heating needs in the considered Belgium climate

\begin{tabular}{lll}
\hline Buildings & \multicolumn{2}{l}{ Heating requirements $\left(\mathrm{kWh} / \mathrm{m}^{2}\right.$ year $)$} \\
\cline { 2 - 3 } & Initial situation & First floor \\
\hline A1 & 15.0 & 14.0 \\
A2 & 12.0 & 12.0 \\
A3 & 14.0 & 13.0 \\
A4 & 19.0 & 20 \\
A5 & 20.1 & 20.1 \\
A6 & 20.0 & 21.0 \\
A7 & 18.0 & 19.0 \\
A8 & 12.0 & 11.0 \\
A9 & 13.0 & 12.0 \\
A10 & 13.0 & 11.0 \\
Mean & 15.6 & 15.3 \\
\hline
\end{tabular}


administrative data concerning the current operation of the buildings or neighborhood; specific or adjusted seizures for energy, water, waste, and transport (Nematchoua, 2020).

The software interface is structured around five axes: (1) Library: Environmental Impact Data Libraries, General Calculation Characteristics. In this research, we considered a constant value for surplus of materials at the site which is $5 \%$, default typical service life of families of elements such as interior and exterior doors for 30 years, life of global equipment was assumed 20 years, glazing 30 years, coating 10 years; distance of transport: site of production towards building site $100 \mathrm{~km}$, site towards inert discharge finally of life: $20 \mathrm{~km}$. (2) Project: Project management with structure data for any type of project and use of the building with the EQUER engine (Nematchoua, 2020). In this research, we also assumed constant values for the following variables: Loss of electrical network from 9 to $40 \%$ according to the country. Water system yield: $80 \%$, hot water consumption $40 \mathrm{~L} /$ day/ person; cold water consumption $100 \mathrm{~L} /$ day/person; Selective collection of glass: yes; sorted glass: $90 \%$; incinerated waste $40 \%$; recovery to incineration: yes; substituted energy: gas or fuel oil (depending on the country); recovery yield: $80 \%$; selective collection of paper: yes; sorted paper: $80 \%$; distance from the site to the garbage dump: $20 \mathrm{~km}$; distance from the site to the incinerator: $10 \mathrm{~km}$; distance from the site to the recycling center: $100 \mathrm{~km}$ (Nematchoua, 2020). (3) Experimentation: Specific seizures PEBN E+C-; (4) Calculation and results: Start the calculations and consult the results. (5) Neighborhood: Neighborhood Management. The different ranges used in this research are detailed in the next section.

\subsection{Health scale}

The scale used for the health impact in this study is reported in Table 2. This table shows different health intensities on several scales for an eco-neighborhood of 219 inhabitants in Belgium.

In the next section, it is mentioned a method allowing to mitigate the health damage.

\subsection{Mitigation of health impacts}

In this paper, we investigated the impact of photovoltaic panels combined with sustainable inhabitants' mobility on the health impact of the studied neighborhood. In this case, all the electricity used came from the electricity grid of each country, and the production impacts were taken into account. In this new configuration, we will have a photovoltaic system on all the roofs on the site. Installed photovoltaic panels cover a total area of $580 \mathrm{~m}^{2}$ equivalent to a peak power around $83 \mathrm{~kW}$. It must be noted that these buildings use electricity only for light and to power household appliances (Nematchoua, 2020). The installed system will consist of mono crystalline

Table 2 Scale of interpretation to assess the meaning of the health impact intensities

\begin{tabular}{ll}
\hline Intensity (DALY) & Meaning \\
\hline $0.0-0.2$ & Very low \\
$0.2-0.4$ & Low \\
$0.4-0.6$ & Significant \\
$0.6-0.8$ & High \\
$0.8-1.0$ & Very high \\
\hline
\end{tabular}


photovoltaic solar panels. The sensors will be placed using a support on the roof terraces. They are oriented toward the South in the northern hemisphere and toward the North in the southern hemisphere. They are inclined at $37^{\circ}$ for the countries located in the temperate zones and inclined at $45^{\circ}$ for the countries located in the hot zone. These panels have thus an optimal orientation and inclination in all the countries. The maintenance time is every 6 months. The energy payback time (EPBT) of this PV system calculated is 3.2 years, this mean, we will get energy free of cost for 26.8 years assuming that the lifetime of the system is 30 years. We assume in this study that the reduction rate per year of PV is very low (negligible), so well that its efficiency in the same during all his lifecycle (Nematchoua et al., 2019e).

We then performed the thermal simulation of each building and completed the final LCA of the neighborhood. In the next step, we investigated the impact of mobility on the neighborhood 'health record. In our basic scenario, we considered an important utilization of the car for daily commuting. We are going to compare this hypothesis (scenario) with a second one, where the study place is supposed urban, perfectly adapted with public transport networks and short distance for moving. To recapitulate the mobility hypotheses: (i) Initial scenario: fifty or eighty percent of the occupants commute daily (following the country); the distance from home to work of 5-10 km is carried out daily by car; the distance from home to shops of $1 \mathrm{~km}$ is done weekly by car. (ii) new scenario or "Urban Site" scenario: One hundred percent (100\%) of the occupants make the trip, daily; the distance from home to work of $2-5 \mathrm{~km}$ is done daily by bus; the distance from home to shops of $0.5-1 \mathrm{~km}$ is carried out weekly by bike or on foot (Nematchoua, 2020).

Finally, photovoltaic panels and sustainable mobility have been combined in a mixed scenario to investigate their effect on the health impact assessment. This scenario was mainly applied to the case of 31 representative countries, selected among the 150 studied countries. These selected countries are located in the 5 continents, covering different climatic contexts. These countries were also selected based on their very significant energy mix and local building materials. We set one occupant for $30 \mathrm{~m}^{2}$ in the case of developed countries, and one occupant for $10 \mathrm{~m}^{2}$, in the case of developing countries. For each thermal zone, we defined the ventilation parameters. We consider a good air tightness resulting in infiltration of $0.25 \mathrm{Vol} / \mathrm{h}$ through the wall. The thermal standards limit to $0.6 \mathrm{Vol} / \mathrm{h}$, however, for passive buildings we assume an air tightness having been the subject of a careful study during implementation. Regarding the air renewal, we supposed each person needed to breathe properly around $20 \mathrm{~m}^{3} / \mathrm{h}$. The validation of model are showed in Sect. 2.7.

\subsection{Validation}

To validate our data, we compare our simulated results and data suggested by Burden of Disease (2017). The results are showed in the following Table 3. This analyze was carried out with IBM SPSS Statistical software.

The results given in this table show that the Pearson coefficient is nearby 1 $(\mathrm{R}=0.78)$, this means that the results found in this research are nearby those suggested by WHO. Our results can be accepted.

In the previous section we have detailed the method used in this study. The next section gives some main results. 


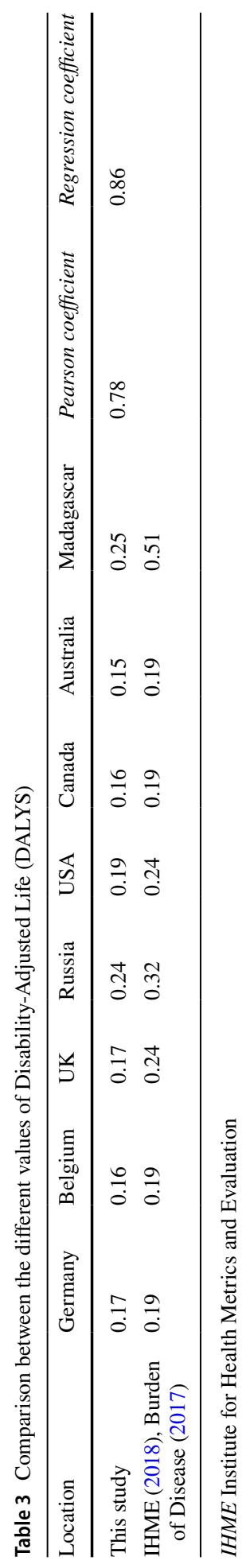




\section{Results and analysis}

This section is divided into four sub-sections. The first one analyzes the weather in Belgium. The second one analyzes the health damage due to the eco-neighborhood located in different countries. The third one analyzes the influence of the new scenario on health damage and the fourth one analyzes the different health damage components. The last section analyzes the impact of the different life cycle stages in terms of health damage in each region. The detailed method is showed in the Fig. 2.

\subsection{Analysis of weather}

It is seen that in the eco-neighborhood, outdoor air temperature varied from -10 to $18{ }^{\circ} \mathrm{C}$ between October and March, while reaching a peak of $33{ }^{\circ} \mathrm{C}$ in July during the summer. Temperature alternation impacts human health (Nematchoua et al., 2017a). In addition, on the basis of our simulation results, the comfort rate depends on the air temperature. In Belgium, at $18{ }^{\circ} \mathrm{C}$, comfort rate is $77 \%$ while at $30{ }^{\circ} \mathrm{C}$, thermal comfort decreases to $3 \%$ in Belgium. Globally, in this country, the comfort rate decreases when the temperature increases. Regarding the six parameters affecting the thermal comfort (metabolism, clothing, air speed, temperature, relative humidity, and radial temperature), both the temperature and relative humidity are the most important parameters that directly affect human health (Nematchoua et al., 2017b, 2017c). At a certain temperature threshold, the occupant is subjected to stress, headaches, fever, etc. (Nematchoua et al., 2017a). The next section evaluated the health damages per country.

\subsection{Analysis of the health damages}

Figures 3 and 4 show the health vulnerability in the studied neighborhood located in 150 countries and some regions. In Fig. 3, the health damage is "high" (0.6-0.8 DALYS/ year) in some countries such as Poland, Cuba, Madagascar, Taiwan, and Niger and is "significant" (0.4-0.6 DALYS/year) in China, India, Bolivia, Cameroon, and Singapore. The health damage is "low" (between 0.2 and 0.4 DALYS/year) in Canada, Brazil, South Africa, Tanzania, Germany, and France. It is interesting to notice that the health damage is "low" in USA, UK, Russia, Kazakhstan, and Australia. Indeed, the analysis of these results shows that in the majority of cases, the health damage is important in countries where the energy mix is essentially composed of fossil energy, and low in countries in progress with renewable energies. Figure 4 evaluates the health damage generated by the studied neighborhood in some regions. The health damage is $22 \%$ higher in Africa than in Europe and 54\% lower in North Europe than in Caribbean America. Globally, the health damage is 17\% higher in South America than North America, 3\% higher in West Africa than Central Africa, 3.9\% lower in West Asia than South Asia and 23.6\% higher in North Africa than South Europe, yet as equal as in Australia and Northern Europe. The implementation of renewable energies thus makes it possible to limit greenhouse gas emissions which have an impact on global warming. This can have direct or indirect consequences on health. For example, a sudden change in temperature and relative humidity can generate certain diseases at human, such as headaches, fever, etc. 
Fig. 2 Research conceptual framework

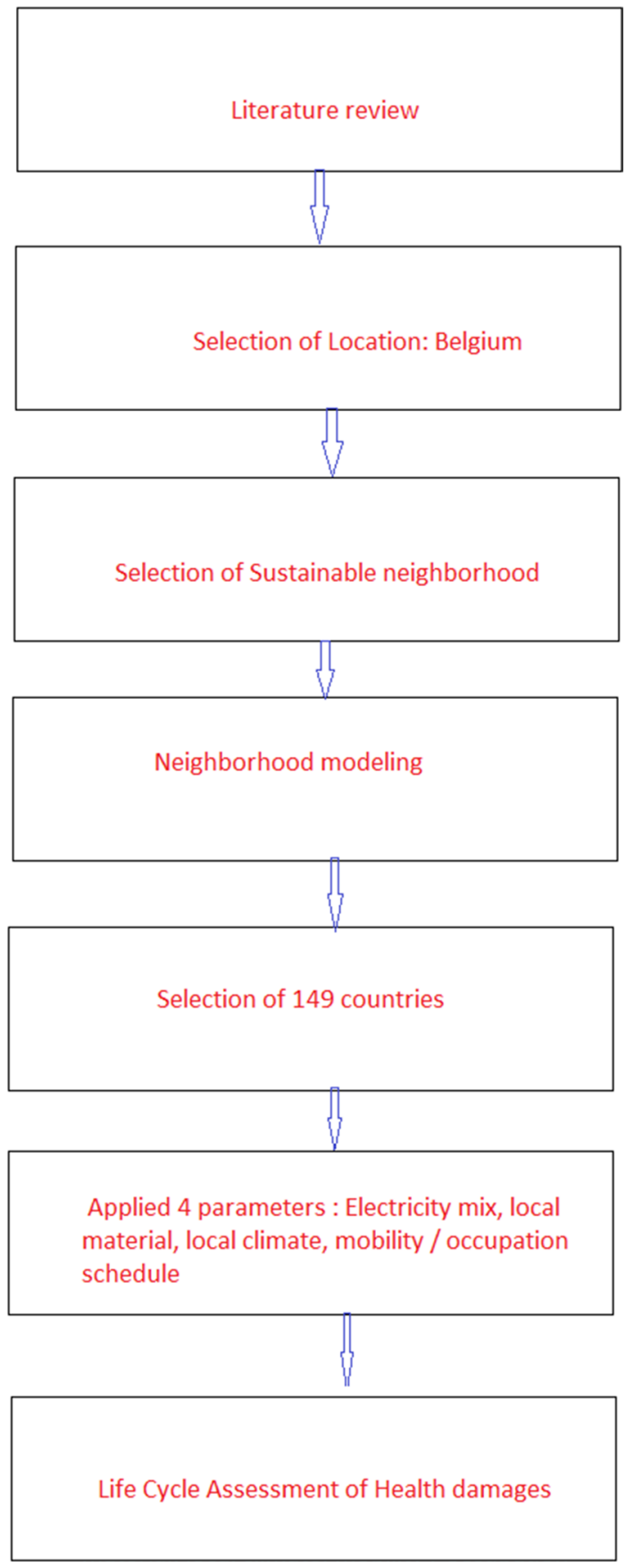




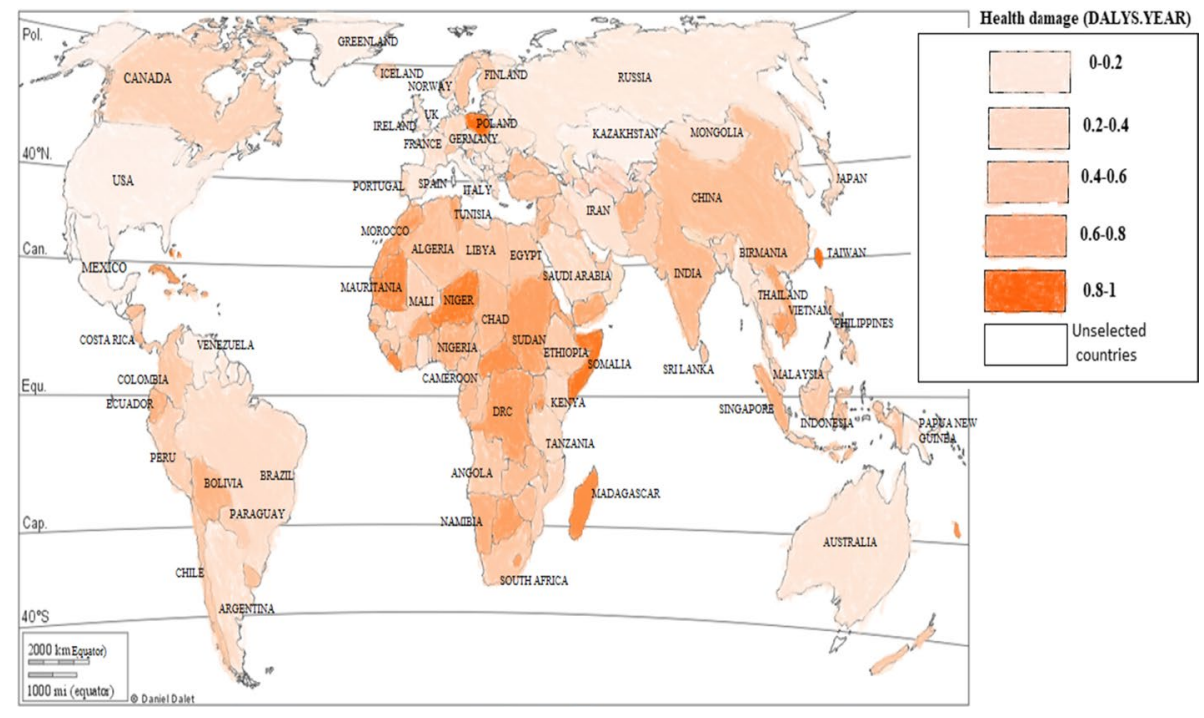

Fig. 3 Health damage assessment generated by an eco-neighborhood designed in 150 countries

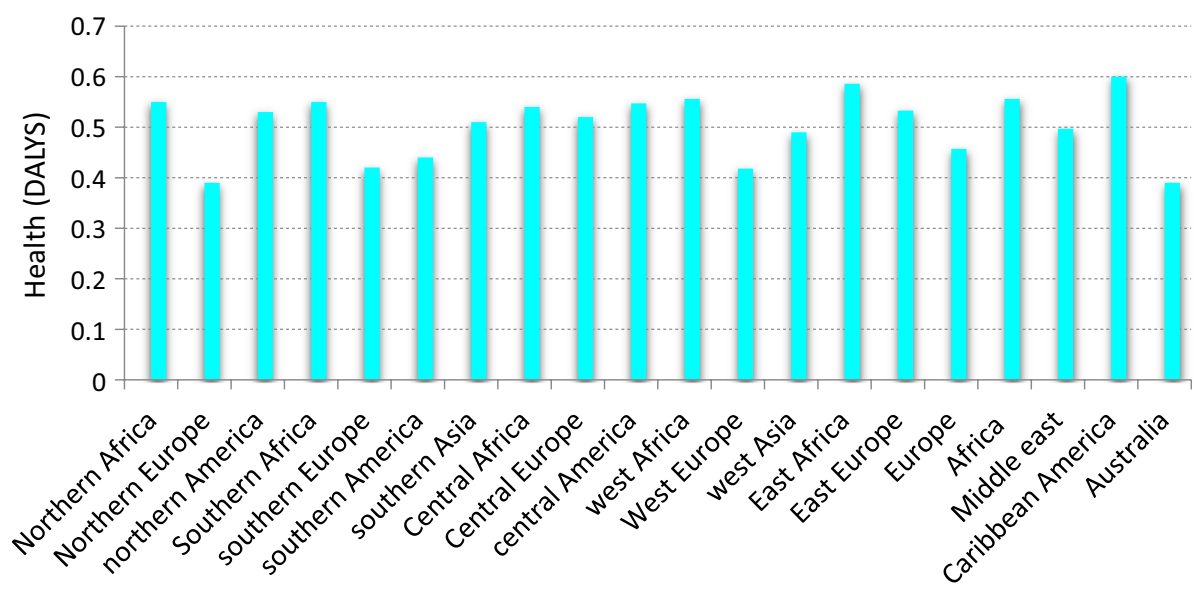

Fig. 4 Health damage evaluation generated by an eco- neighborhood designed in some regions

Some scenarios are given in the next sub-section.

\subsection{Analysis of scenario impacts}

Figure 5 compares the health damage impact of the "initial" and "photovoltaic" scenarios over 100 years. The global implementation of green mobility and photovoltaic panels reduces on average $5.2 \%$ of other health damages by this neighborhood for all the studied countries (see Fig. 5). Overall, in the majority of countries located in a temperate climate, the health damage decreases by an average of 5.8\% according to this scenario, while for the countries in the hot region (Indonesia, Singapore, Iran, Nigeria, Egypt, etc.) the 


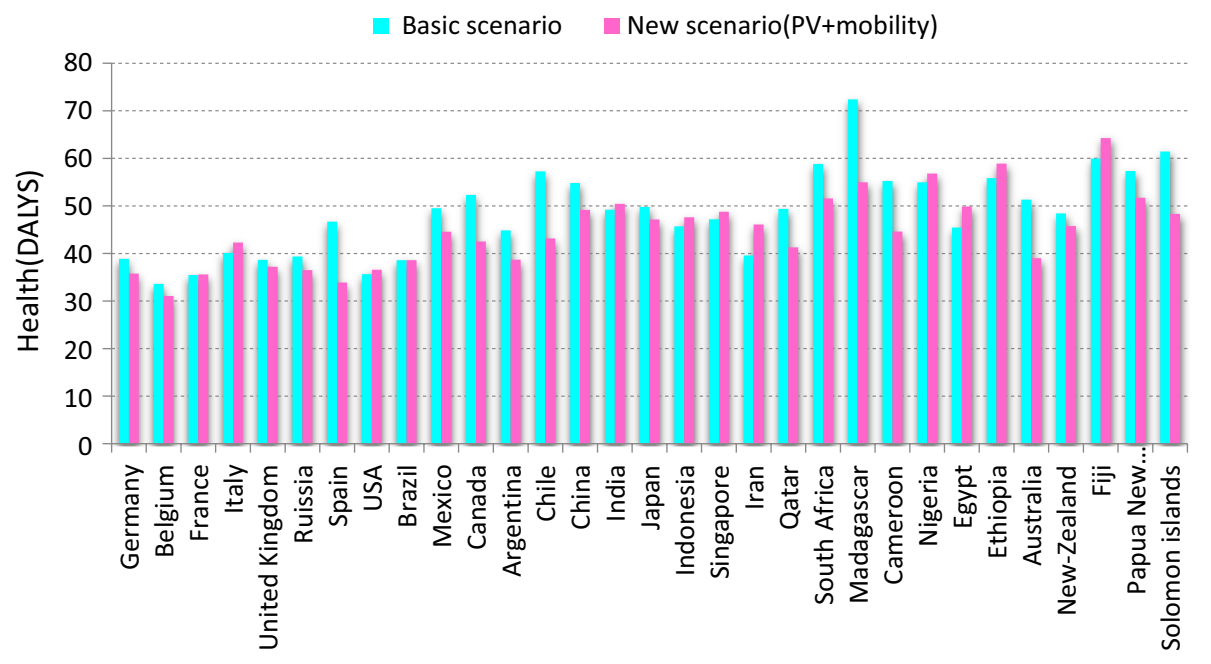

Fig. 5 Comparative Diagram of the health damage impact of the "Initial" and "Photovoltaic" Scenarios (Functional Unit: Entire neighborhood) over 100 years

health damage increases by an average of $1.9 \%$. These results show that the effects of solar panels implementation are not always positive. Moreover, the health impact deviates from the average value in some countries: for example, this new scenario allows mitigating the health damage to $8.1 \%$ in Germany, $7.2 \%$ in Russia, $18.7 \%$ in Canada, 23.9\% in Australia, $32.7 \%$ in Chile, $31.8 \%$ in Madagascar, and $5.4 \%$ in Ethiopia.

These results showed that the implementation of the photovoltaic panels has significant effects on health improvement or degradation, according to the country concerned. The health damage due to pollutants emitted in living environments or neighborhoods was established in 2006 by Aubert (2006). In fact, a high level of nitrogen dioxide aggravates cardio-respiratory diseases (USEPA, 1996; Nematchoua et al., 2018 and 2019e). Lead increases the risk of cardiovascular disease and infant lead poisoning (Fischbein, 1992), and sulfur dioxide emitted regularly by man is carcinogenic (soskolne et al., 1989). In high concentrations, particles and sulfur dioxide would cause an increase in mortality of nearly a quarter (Hertzman, 1995). In addition, the presence of landfills is associated with high rates of congenital malformations (Dolk et al., 1998), and ash, heavy metals, and dioxins emitted by incinerators are associated with high rates of cancer, respiratory disease and congenital malformations (ALLsopp, 2001). The health effects of pollutants vary according to their concentrations and combinations as well as to the exposure and vulnerability of individuals (ATSDR, 2005).

\subsection{Analysis of environmental components}

Figures 6, 7, 8 and 9 show the frequency of the different environmental components in the generation of the health damage in 28 representative countries located in the five continents of the world (Europe, America, Africa, Asia, and Oceania). In the majority of countries, building materials and electricity are the main origins of health degradation according to the eco-neighborhood life cycle (Figs. 7 and 8). The health damage caused by transportation and waste is the highest in European countries (8.9\%) and the lowest in 


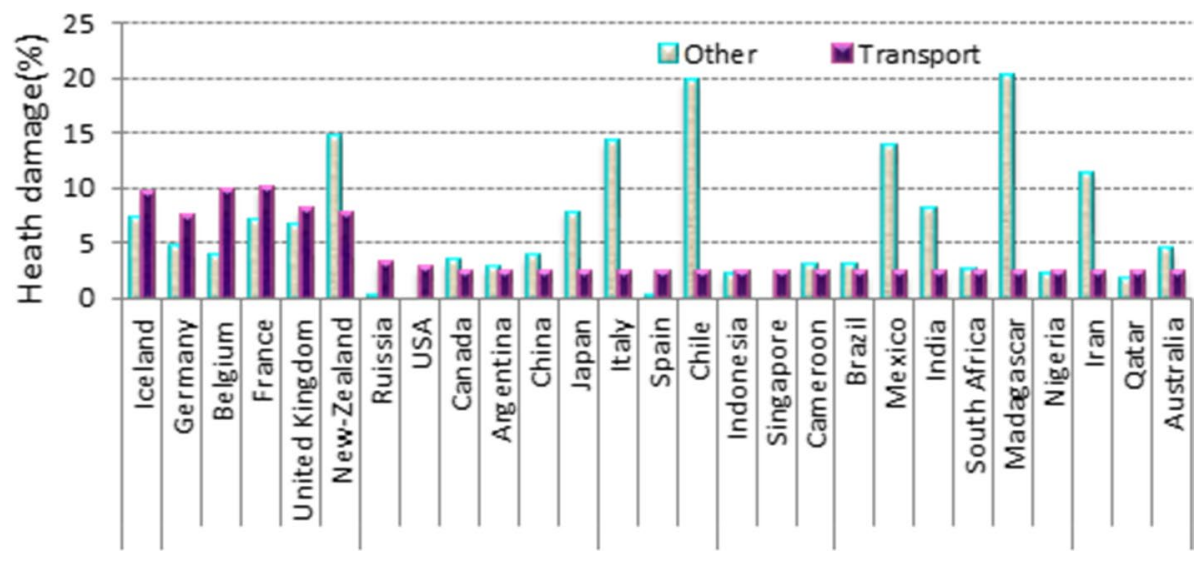

Fig. 6 Frequency (in \%) of the different environmental components (transport and other) in the generation of the health damage, for some representative countries located in several climatic contexts

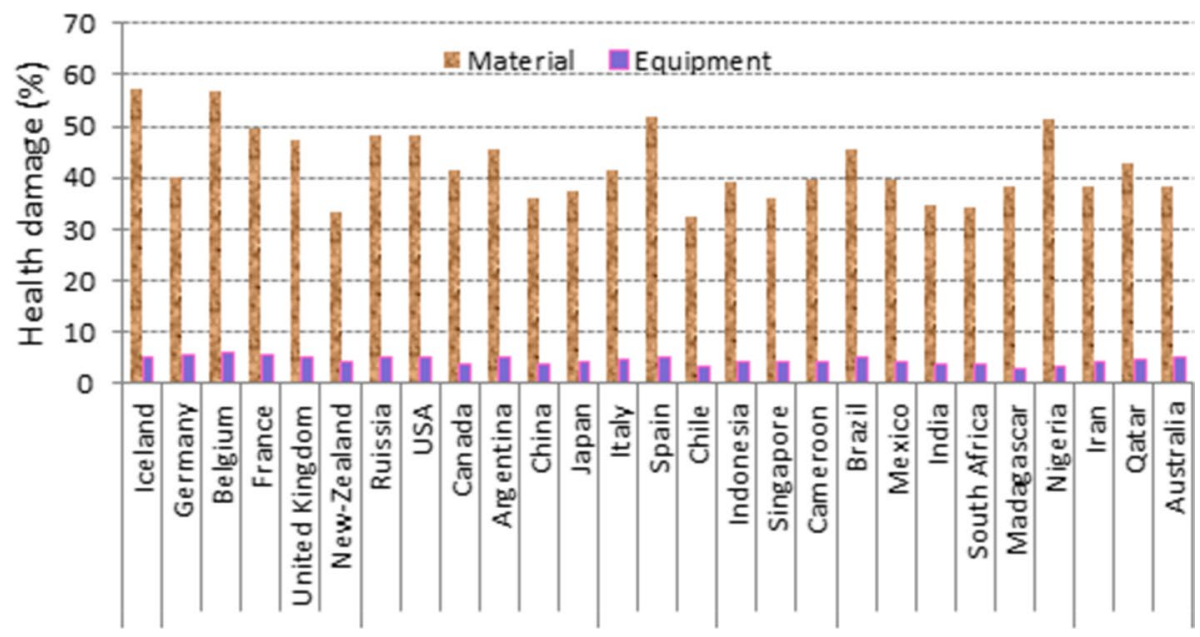

Fig. 7 Percentage of the different environmental components (material and equipment) in the generation of the health damage, for some representative countries located in several climatic contexts

Africa (5.7\%). The health damage produced by material degradation was $57.2 \%$ in Iceland, $51.7 \%$ in Spain, $51.4 \%$ in Nigeria and $47.4 \%$ in the UK. Electricity is also one of the main environmental component of health damage in China and Germany (32.7\% of total sources or total components) as well as in Singapore and South Africa (34.4\%).

Overall, the health damage produced by building heating is more important in Canada (17.8\%), in France (10.7\%), and in Russia (5.1\%), as shown in Fig. 8. 5.4\% and 4.5\% of the health damage is produced by transportation and equipment, respectively, as shown in Figs. 6 and 7. As illustraed in Figs. 7 and 8, 42.4\% and 26.2\% of the health damage is produced by building material and electricity production, respectively. In addition, as presented in Fig. 9, 8.5\% and 5.3\%, of the health damage is produced by waste and water.

In polar climate (Iceland, Greenland), the waste and water use causeonly $1.6 \%$ and $5.4 \%$ of the health damage, respectively. In Oceanic climate (Germany, Belgium, France, and the 


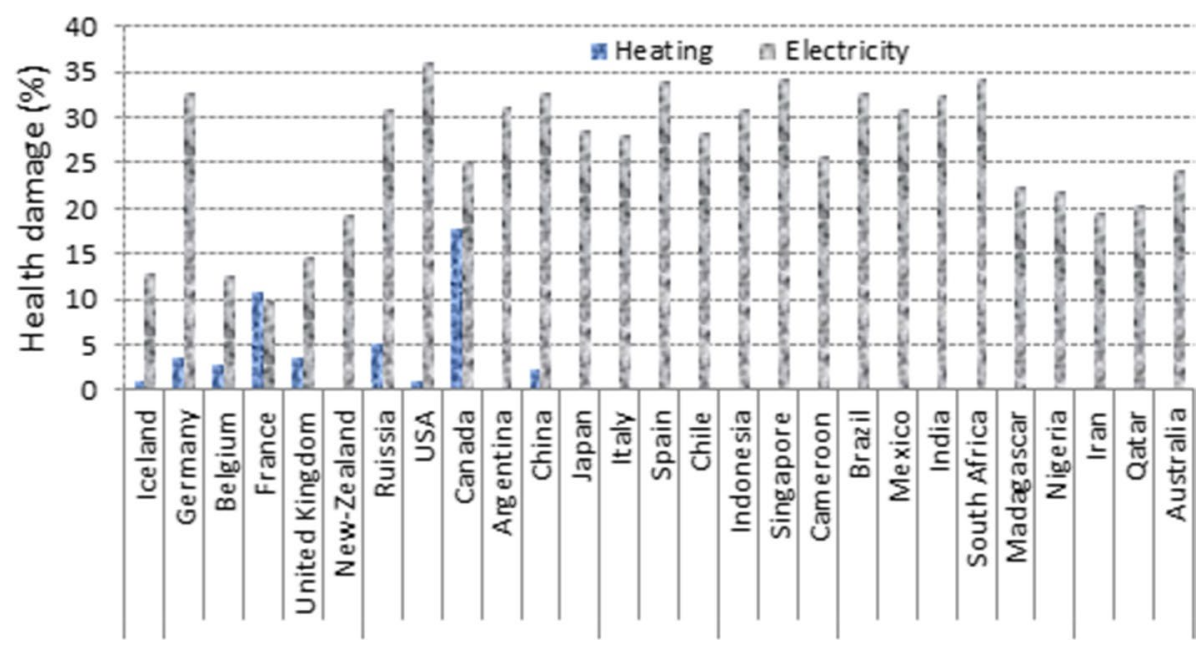

Fig. 8 Percentage of the different environmental components (heating and electricity) in the generation of the health damage, for some representative countries located in several climatic contexts

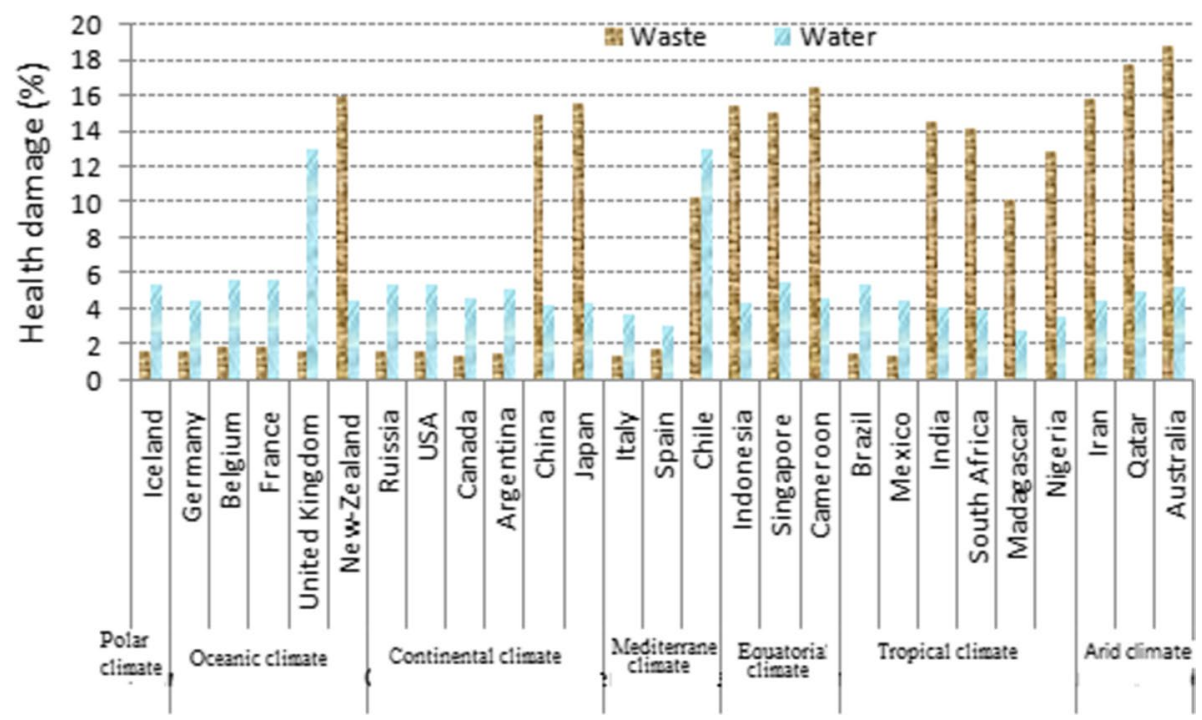

Fig. 9 Percentage of the different environmental components (Waste and water) in the generation of the health damage, for some representative countries located in several climatic contexts

UK), the waste and water cause $4.1 \%$ and $6.5 \%$ of the health damage, respectively. In continental climate (Russia, USA, Canada, Argentina, China, and Japan), the waste and water result in $6.1 \%$ and $4.8 \%$ of the health damage, respectively. In Mediterranean climate (Italy, Spain, Chile), waste and water lead to $4.5 \%$ and $6.6 \%$, of the health damage, respectively. In equatorial climate (Indonesia, Singapore, Cameroon), the waste and water produce $15.6 \%$ and $4.8 \%$ of the health damage, respectively. In tropical climate (Brazil, Mexico, India, South Africa, Madagascar, and Nigeria), the waste and water produce $15.8 \%$ and 
4.7\% of the health damage, respectively. Finally, in Arid Climate (Iran, Qatar), the waste and water lead to $17.5 \%$ and $5.1 \%$ of the health damage, respectively. These results showed that the impact of waste on the health degradation is the most significant for the countries located in an arid climate.

May be, because in some countries located in arid climate, the electricity mix is majority constituted of oil which generates a great quantity of waste.

The health damage is estimated around 0.55 DALYs/year, in Northern Africa. These ones come from transportation (4.2\%); electricity (27.3\%); heating (2.3\%); building material $(30.5 \%)$; equipment $(3.2 \%) \ldots$ It's also important to notice that the health damage is produce by building heating $(3.5 \%)$, electricity $(14.6 \%)$; waste $(1.2 \%)$; transportation (8.1\%); building material (47.3\%) etc.

The next section evaluated the health damage per capita.

\subsection{Analysis of life cycle stages and health damage per habitant}

Figure 10 shows the health damage generated by different life cycle stages of an econeighborhood. Overall, the operation stage produces over $50 \%$ of health damage of its life cycle, compared to the construction stage (34.8\%) and the maintenance stage (9.7\%). These results show that the use stage generates the most important health damage in a sustainable neighborhood.

The yearly health damage in the eco-neighborhood varied according to the regions, as shown in Fig. 11. Indeed, the health damage is estimated to 0.0021 DALYS/inhabitant in Europe, 0.0025 DALYS/inhabit. In Africa and 0.027 DALYS/inhabit. In Caribbean America. These results show that the health damage is smaller in Europe than Africa. In addition, the health damage is 0.0025 DALYS/inhabit., 0.0019 DALYS/inhabit. And 0.0023 DALYS/inhabit., in Southern Africa, Southern Europe, and Southern Asia, respectively. These results show that health damage per occupant is the most significant in Africa. Health damage per square meter of living space per year is very low and negligible.

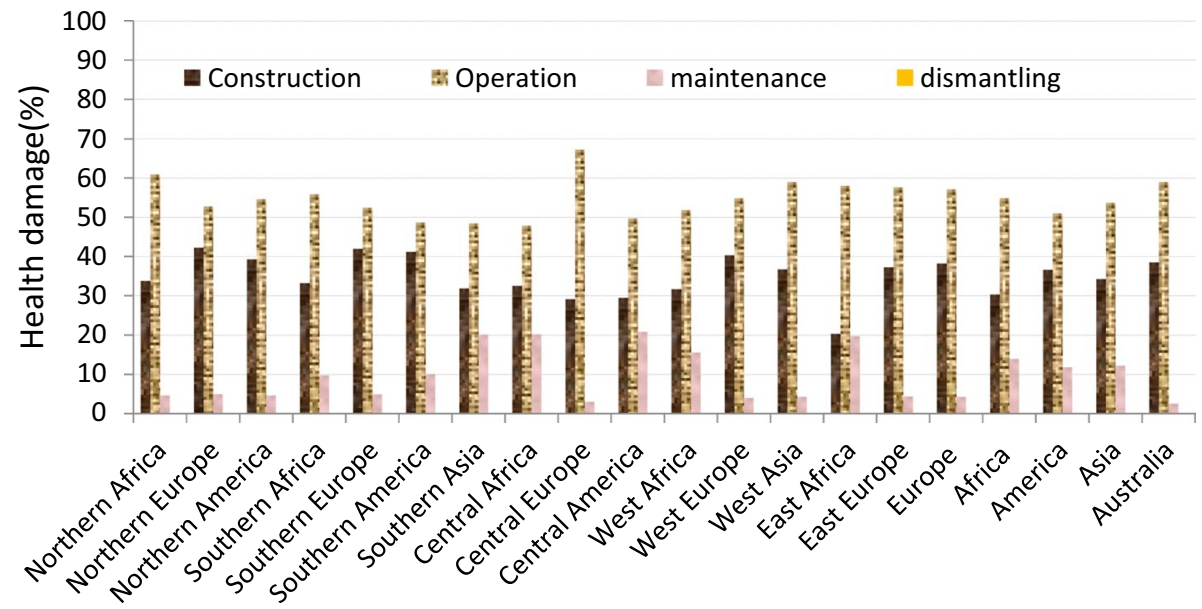

Fig. 10 Health damage generated by each stage of life cycle at the eco-neighborhood scale designed in some regions 


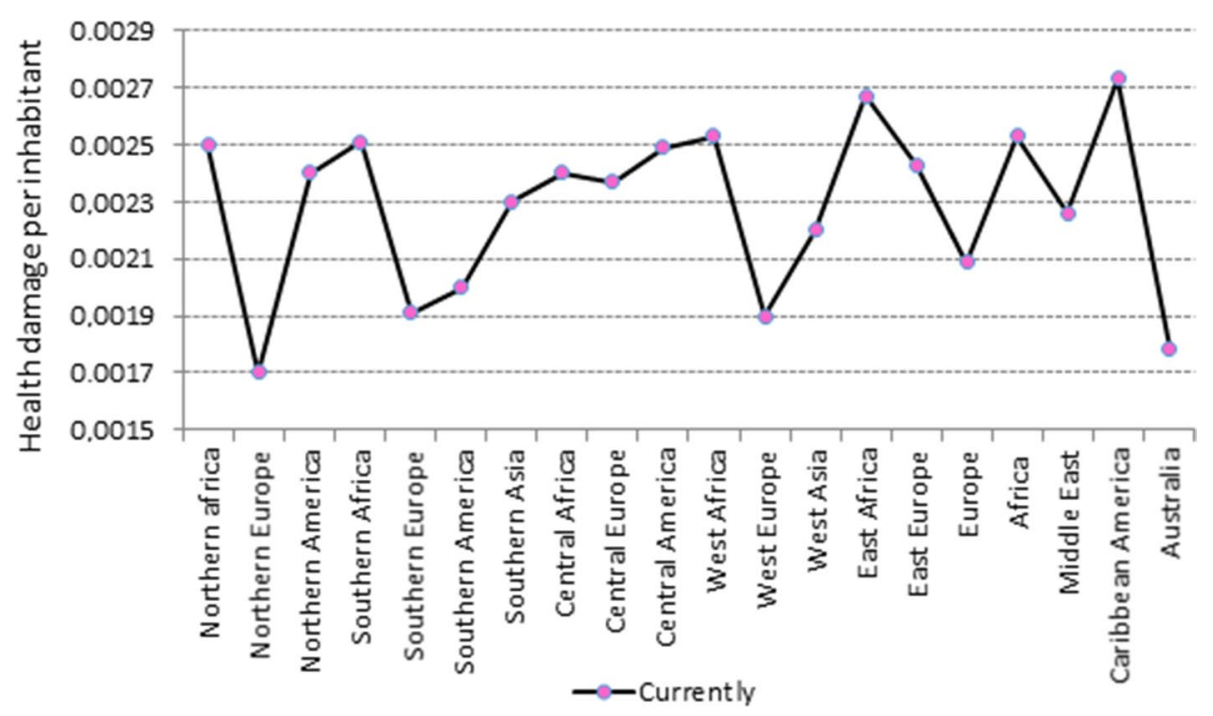

Fig. 11 Health damage generated by each occupant living in the eco-neighborhood

\section{Discussions}

This study shows that the health damage due to a neighborhood varies widely according to the different countries and climates. Rossi et al. (2012a) found that at the building scale, energy mix has a significant influence on greenhouse gas emissions. The health damages generated by an eco-neighborhood of 219 inhabitants were found to be "low" in some countries, such as USA, UK, Australia, and Russia; "very high" (from 0.7 to 1.0 DALYS/ year) in Bolivia, Poland, Madagascar. In 2016, it was seen that the coal represented 65\%, and $57 \%$ of the energy mix in China, and Poland, respectively. In addition, the energy mix was constituted of $56 \%$ of fuel in Bolivia and $66 \%$ in Madagascar. It was also observed that the fossil fuel energy sources considerably increased the health damage indicting the significant impacts of energy mix on human health.

As shown in Fig. 5, photovoltaic panels installed on the building roofs have a minor influence on the health impact in the neighborhood life cycle. Indeed, on average, 5.2\% of health damage is mitigated with the implementation of photovoltaic solar panels in this eco-neighborhood. According to some studies (Fthenakis, 2004; Goetzberger \& Hoffman, 2005; Tsuo et al., 1999), electricity produced under the base of solar photovoltaic panels has no impact on health, because photovoltaic systems do not use fossil fuels.

Thus, they do not emit dangerous and toxic gases or greenhouse gas related to fossil fuels. U.S. Dept. of Energy, in one of its report in 2010 emphasized the little environmental impacts of most of the renewable energy recourses such as solar photovoltaic panels (U.S. Dept, 2010). However, being considered as a source of energy, the total life cycle of photovoltaic products can present potential risks for the environment and human health (U.S. Dept., 2009).

The building materials and electricity are the main sources of health damage in an econeighborhood. These results are not surprising; they confirm the research of Nematchoua et al., (2015a, 2015b) who showed that building materials in a hot climate contribute to the emission of toxic pollutants affecting human health. These results are also in line with 
those of Hainoun et al. (2010) showing that the impact on the health coming from the electricity production varies according to the techniques of productions; for example, electricity generation by gas-fired plants has a slight effect on health, while coal-fired and thermal plants emit carbon dioxide and sulfur, which have a direct impact on human health.

$5.4 \%$ and $4.5 \%$ of health damage of the eco-neighborhood are produced by transportation and equipment. The modes of daily commuting have an impact on the health, it would be better to opt for short distances (less than $12 \mathrm{~km}$ ) by bike and for displacements with longer distance by bus or train as explained by Nematchoua et al. (2019a). This research also shows that in some countries, such as France, Canada, Russia, the heating of buildings have a significant influence on human health. Van Marken Lichtenbelt et al. (2009) explained that the time spent indoors under almost uniform temperature had negative effects on health. Later, in 2013, Bluyssen (2018) claimed that living in an environment at temperatures below $20{ }^{\circ} \mathrm{C}$ can help prevent obesity. Nevertheless, it is noticed that the degree of heating in a residential building can have an impact on the sleep of the occupants. The desires and requests vary according to the occupants: some people are accustomed to leaving the windows open while stopping the heating even under an extreme cold in winter, while others prefer to live on a constantly heated residence. Today, no standard specifies the guidelines for having the best quality of sleep. What is known is that the overheating of the building reduces the quality of sleep.

This study also showed that the impact of waste on the health degradation in the neighborhood is more important in the countries located in an arid climate than other climates. Finally, health damage/inhabitant in the eco-neighborhood is the most important in Africa. Compared to other regions of the world, Africa is the continent that pollutes the least, but, nevertheless suffers the most environmental damage and health impacts. For example, the island of Madagascar located in Africa is one of the world's most vulnerable countries due to climate change and health damage. The causes are multiple. Is it due to bad government policy? Is it due to the high level of poverty in this continent? Is it due to the high birth rate? or, is it due to civil and tribal war?

Note that the global health damage assessed in this study remains lower than the health impacts generated by a conventional neighborhood, due to the fact that it is a sustainable neighborhood. According to the European Union (Environment \& Health, 2016) about $20 \%$ of diseases, occurring in industrialized countries can be reduced by living in an ecological environment such as an eco-neighborhood. After discussing our results it is important to mention some limitations of this study as given in the next section.

\section{Limitations and strength of this scientific research}

\subsection{Originality and novelty}

(1) Several researches based on life cycle analysis focus on the case of a country. This research, analysis, compares the case of the LCA of human health damage of 150 countries. (2) The application of photovoltaic panels to reduce the impact of health damage at the district level. (3) Several LCA studies are concentrated in the case of simulation. (4) No research work in the literature has yet been carried out showing in detail the differences in health damage in Africa and in certain underdeveloped countries on the scale of an Eco-district. 


\subsection{Limitations}

This research, such as any other scientific research shows some weaknesses.

We studied only the case of a sustainable district; it would have been preferable to also study the case of the most conventional districts. We assessed a single environmental impact, it would have been preferable to analyze several impacts at the scale of the district. It might have been preferable to concentrate on the case of a country, because extending this research to the scale of several countries requires several hypothesis. We did not assess health damage in the future, indeed global warming can have a significant effect on health damage. All these different points cited were not taken into account as a hypothesis during the simulation of this district, so they are considered as the limits of this study. The implementation of all these limits in this study or in a new study would make it possible to have more reliable results with a smaller margin of error and closer to reality. It would has been better to separate the effects of PV and mobility, because, it is difficult to conclude if PV has a positive or negative effect.

Despite this, we believe that this study can be very beneficial to future researchers in this area.

\section{Practice and global implications}

Several results found in this research can complement the conclusions found by FernándezSánchez et al. (2015), Sanjuan-Delmás et al. (2014) and Romero-Gámez et al. (2012) etc. The analysis of health damage from a neighborhood needs to be deepened and minutely studied. This research can help governments, politicians, NGOs in decision-making. Health damage is more important in Africa compared to some continents; a radical and systematic measure must be taken aiming at its reduction. It is important to raise awareness the population.

\section{Conclusions}

This research focuses on the life cycle assessment of human health impacts in an econeighborhood located in Belgium. The same neighborhood is modeled in 149 other countries by respecting some parameters specific to each country, such as the use of different materials, the heating/cooling systems, the energy mix, the buildings insulation thicknesses, mobility, the climate related to the temperatures. The considerable impact of pollution on human health is certainly not disputed. However, it is very difficult to evaluate it in a more precise way. It is found that the energy mix has the most significant effect on human health damage. In some countries such as Germany, Costa Rica, Denmark, Netherlands, Sweden, and Switzerland, where the use of renewable energy is high, $\mathrm{CO}_{2}$ emission which affects human health is low. The health damage is significant in China, Poland, and India which has an energy mix widely composed of coal. In the majority of countries, building materials are the main origin of health degradation in the studied eco-neighborhood. Installing photovoltaic panels in an eco-neighborhood mitigates on average $5.2 \%$ of its health damage. In a sustainable neighborhood, electricity consumption is also one of the main origins of health degradation. Globally, health damage is higher in Africa than in 
other continents. Indeed, it mainly come from the electricity production and transport. The results found in this study may be generalized for all the world countries because this study is distributed through 150 countries in all the five continents covering the three main climatic zones (temperate, polar and hot). It is encouraged to develop a country-specific government policy aimed at popularizing sustainable neighborhoods around the world as well as developing sustainable assessment tools improving neighborhood design and reducing their environmental impacts, including human health. In perspective, we will compare the health damage due to old and conventional neighborhoods with results of this study focusing on the health impacts of an eco-neighborhood. We will evaluate the health damage expressed per $\mathrm{m}^{2}$ and per year in different categories of cities.

\section{References}

ALLsopp, M., cosTner, P., \& Johns Ton, P. (2001). Incineration and Human Health, State of Knowledge of the Impacts of Waste Incinerators on Human Health, Greenpeace Research Laboratories, University of Exeter, UK.

Altomonte, S., Allen, J., Bluyssen, P. M., Brager, G., Heschong, L., Loder, A., Schiavon, S., Veitch, J. A., Wang, L., \& Wargocki, P. (2020). Ten questions concerning well-being in the built environment. Building and Environment, 180, 106949.

ATSDR (agency For Toxic substances and disease registry) (2005). Public health statements. http://www. atsdr.cdc.gov/phshome.html

Aubert, C. (2006). Espérance de vie, la fin des illusions. Mens, Terre vivante (coll. Ecology Society), 160 p.

Bluyssen, P. M. (2018). What do we need to be able to (re)design healthy and comfortable indoor environments? Intelligent Buildings International. ISSN: 1750-8975 (Print) 1756-6932 (Online) Journal homepage: https://www.tandfonline.com/loi/tibi20

Briggs, X. S., Comey, J., \& Weismann, G. (2010). Struggling to stay out of high-poverty neighborhoods: housing choice and locations in moving to opportunity's first decade. Housing Policy Debate, 20, 383-427.

Burden of Disease (2017). Retrieved January 25, 2020, from https://ourworldindata.org/burden-of-disease.

Carr, L. J., Dunsiger, S. I., \& Marcus, B. H. (2010). Walk score ${ }^{\mathrm{TM}}$ as a global estimate of neighborhood walkability. American Journal of Preventive Medicine, 39, 460-463.

Dolk, H., Vrijheid, M., et al. (1998). Risk of congenital anomalies near hazardouswaste landfill sites in Europe: The EUROHAZCON study. Lancet, 352, 423-427.

Eckelman, M. J., Sherman, J. D., \& Mac Neill, A. J. (2018). Life cycle environmental emissions and health damages from the Canadian healthcare system: An economic-environmental epidemiological analysis. PLoS Medicine, 15(7), 1002623. https://doi.org/10.1371/journal.pmed.1002623

Environment and Health: For a coherent approach on every level (2016). Retrieved June 2019, from https:// www.health.belgium.be/en/environment-and-health-coherent-approach-every-level.

Fernández-Sánchez, G., Berzosa, Á., Barandica, J. M., Cornejo, E., \& Serrano, J. M. (2015). Opportunities for GHG emissions reduction in road projects: A comparative evaluation of emissions scenarios using CO2NSTRUCT. Journal of Cleaner Production. https://doi.org/10.1016/j.jclepro.2015.05.032

Fischbein, A. (1992). Occupational and environmental lead exposure. In W. N. Rom (Ed.), Environmental and Occupational Medicine (pp. 735-758). Little Brown.

Foster, S., \& Giles-Corti, B. (2008). The built environment, neighborhood crime and constrained physical activity: An exploration of inconsistent findings. Preventive Medicine, 47, 241-251.

Fthenakis, V. (2004). National PV Environmental Research Center: Summary Review of Silane Ignition Studies. http://www.bnl.gov/pv/abs/abs_149.asp

Galin, J., Abrams, B., Leonard, S. A., et al. (2016). Living in violent neighbourhoods is associated with gestational weight gain outside the recommended range. Paediatric and Perinatal Epidemiology, 31, 37-46.

Gaurisankar, S., \& Tanya, D. (2008). Anti cancer effects of curcumin: cycle of life and death. Cell Division, 3, 14. https://doi.org/10.1186/1747-1028-3-14

Gervasio, H., Santos, P., da Silva, L.-S., Vassart, O., Hettinger, A.-L., \& Huet, V. (2014). Large valorisation on sustainability of steel structures, background document. Portugal. ISBN 978-80-01-05439-0 
Goedkoop, M. J., \& Spriemsma R. (2001). The Eco-Indicator 99, A dammage oriented method for life cycle impact assessment, methodology report, methodology annex, manual for designers, Amersfoort, June 2001

Goetzberger, A., \& Hoffman, V. (2005). Photovoltaic solar energy generation. Springer. http://www. washingtonpost.com/wp-dyn/content/article/2008/03/08/AR2008030802595.html

Hainoun, A., Almoustafa, A., \& Aldin, M. S. (2010). Estimating the health damage costs of syrian electricity generation system using impact pathway approach. Energy, 35, 628-638.

HCSP. (2009). High Council of Public Health. https://www.hcsp.fr, p 1-60, Acessed on April 06, 2021

Headen, I., Mujahid, M., Deardorff, J., et al. (2018). Associations between cumulative neighborhood deprivation, long-term mobility trajectories, and gestational weight gain. Health \& Place, 52, 101-109.

Hertzman, C. (1995). Environment and Health in Central and Eastern Europe. World Bank.

IHME: Institute for Health Metrics and Evaluation. (2018). Accessed on April 5, 2021. http://www.healt hdata.org/.

Janevic, T., Stein, C. R., Savitz, D. A., et al. (2010). Neighborhood deprivation and adverse birth outcomes among diverse ethnic groups. Annals of Epidemiology, 20, 445-451.

Kelly, M. (2019). Our space: a neighborhood database. Kelly Research \& Outreach Lab website. Retrieved March 5, 2019, from https://maggi-kelly.squarespace.com/our-space/.

Laraia, B., Messer, L., Evenson, K., et al. (2007). Neighborhood factors associated with physical activity and adequacy of weight gain during pregnancy. Journal of Urban Health, 84, 793-806.

Liu, S. R., Kia-Keating, M., Santacrose, D. E., \& Modir, S. (2018). Linking profiles of neighborhood elements to health and related outcomes among children across the United States. Health and Place, 53, 203-209.

Maliene, V., \& Malys, N. (2009). High-quality housing-A key issue in delivering sustainable communities. Building and Environment, 42, 426-430.

Messer, L. C., Laraia, B. A., Kaufman, J. S., et al. (2006). The development of a standardized neighborhood deprivation index. Journal of Urban Health, 83, 1041-1062.

Messer, L. C., Vinikoor-Imler, L. C., \& Laraia, B. A. (2012). Conceptualizing neighborhood space: Consistency and variation of associations for neighborhood factors and pregnancy health across multiple neighborhood units. Health \& Place, 18, 805-813.

Moore, T. H. M., Kesten, J. M., López-López, J. A., Ijaz, S., Mc Aleenan, A., Richards, A., Gray, S., Savović, J., \& Audrey, S. (2018). The effects of changes to the built environment on the mental health and well-being of adults: Systematic review. Health and Place, 53, 237-257.

Mujahid, M. S., \& Roux, A. V. D. (2010). Neighborhood factors in health. In A. Steptoe (Ed.), Handbook of behavioral medicine: Methods and applications (pp. 341-354). New York: Springer.

Ncube, C. N., Enquobahrie, D. A., Albert, S. M., et al. (2016). Association of neighborhood context with offspring risk of preterm birth and low birthweight: A systematic review andmeta-analysis of population-based studies. Social Science \& Medicine, 153, 156-164.

Nematchoua, M. K. (2020). Simulation of the photochemical ozone production coming from neighborhood: A case applied in 150 countries. Health and Environment, 1(1), 38-47.

Nematchoua, M. K., Asadi, S., \& Reiter, S. (2019d). A study of life cycle assessment in two old neighbourhoods in Belgium. Sustainable Cities and Society. https://doi.org/10.1016/j.scs.2019.101744

Nematchoua, M. K., Jacques, T., \& Reiter, S. (2019b). Statistical life cycle assessment of residential buildings in a temperate climate of northern part of Europe. Journal of Cleaner Production, 229, 621-631.

Nematchoua, M. K., Orosa, J. A., \& Reiter, S. (2019c). Life cycle assessment of two sustainable and old neighbourhoods affected by climate change in one city in Belgium: A review. Environmental Impact Assessment Review, 78, 106282.

Nematchoua, M. K., Orosa, J. A., \& Reiter, S. (2019a). Energy consumption assessment due to the mobility of inhabitants, and multiannual prospective on the horizon 2030-2050. Energy, 171, $523-532$.

Nematchoua, M. K., Orosa, J. A., \& Reiter, S. (2019e). Climate change: Variabilities, vulnerabilities and adaptation analysis-A case of seven cities located in seven countries of Central Africa. Urban Climate, 29, 100486.

Nematchoua, M. K., \& Reiter, S. (2019). Analysis, reduction and comparison of the life cycle environmental costs of an eco-neighborhood in Belgium. Sustainable Cities and Society, 48, 10155.

Nematchoua, M. K., Ricciardi, P., \& Buratti, C. (2017a). Thermal comfort and comparison of some parameters coming from hospitals and shopping centers under natural ventilation; A Case of Madagascar island. Journal and Building Engineering, 13, 196-206. 
Nematchoua, M. K., Ricciardi, P., \& Buratti, C. (2017b). Adaptive approach of thermal comfort and correlation between experimental data and mathematical model in some Schools and traditional buildings of Madagascar under natural ventilation. Sustainable Cities \& Society, S2210-6707(2017b)31030-2.

Nematchoua, M. K., Ricciardi, P., \& Buratti, C. (2017c). Statistical analysis of indoor parameters and subjective responses of building Occupants in a hot region of Indian ocean; a case of Madagascar island. Applied Energy, 208, 1562-1575.

Nematchoua, M. K., Ricciardi, P., Orosa, J. A., \& Buratti, C. (2018). A detailed study of climate change and some vulnerabilities in Indian Ocean: A case of Madagascar island. Sustainable Cities and Society, 41, 886-898.

Nematchoua, M. K., Roshan, G., \& Tchinda, R. (2015b). Climate change and its role in forecasting energy demand in buildings: A case study of Douala City, Cameroon. Journal of Earth System Science, 124(1), 269-281.

Nematchoua, M. K., Tchinda, R., Orosa, J. A., \& Andreasi, W. A. (2015a). Effect of wall construction materials over indoor air quality in humid and hot climate. Journal of Building Engineering, 3, $16-23$.

O’Brien, E. C., Alberdi, G., Geraghty, A. A., \& McAuliffe, F. M. (2017). Lower education predicts poor response to dietary intervention in pregnancy, regardless of neighbourhood affluence: Secondary analysis from the ROLO randomised control trial. Public Health Nutrition, 20, 2959-2969.

Peuportier, B. (2015). Eco-design for buildings and neighbourhoods. Taylor \& Francis Group, 286p.

Peuportier, B., Popovici, E., \& Troccmé, M. (2006). Analyse du cycle de vie à l'échelle du quartier, bilan et perspectives du projet ADEQUA. Build. Environ. 2013.03.017

Pinter-Wollman, N., Jelic, A., \& Wells, N. M. (2018). The impact of the built environment on health behaviours and disease transmission in social systems. Philosophical Transactions of the Royal Society B: Biological Sciences, 373, 20170245. https://doi.org/10.1098/rstb.2017.0245

Popovici, E., \& Peuportier, B. (2004). Using life cycle assessment as decision support in the design of settlements. In PLEA Conference, Eindhoven, September 2004.

Remund, J., Müller, S., Kunz, S., Huguenin, B., Studer, C., \& Cattin, R. (2017). Global meteorological database version 7 software and data for engineers.

Riera Pérez, M. G., \& Rey, E. (2013). A multi-criteria approach to compare urban renewal scenarios for an existing neighbourhood. Case study in Lausanne (Switzerland). Building and Environment, 65, 58-70.

Romero-Gámez, M., Suárez-Rey, E. M., Antón, A., Castilla, N., \& Soriano, T. (2012). Environmental impact of screen-house and open-field cultivation using a life cycle analysis: the case study of green bean production. Journal of Cleaner Production, 28, 63-69.

Rossi, B., Marique, F., \& Reiter, S. (2012a). Life-cycle assessment of residential buildings in three different European locations, basic tool. Building and Environment, 51, 395-401.

Rossi, B., Marique, F., \& Reiter, S. (2012b). Life-cycle assessment of residential buildings in three different European locations, case study. Building and Environment, 51, 402-407.

Salomon, T., Mikolasek, R., \& Peuportier, B. (2005). Outil de simulation thermique du bâtiment, COMFIE, from Journée SFT-IBPSA, Outils de simulation thermo-aéraulique du bâtiment, La Rochelle, 8 p.

Sanjuan-Delmás, D., Petit-Boix, A., Gasol, C. M., Villalba, G., Suárez-Ojeda, M. E., Gabarrell, X., Josa, A., \& Rieradevall, J. (2014). Environmental assessment of different pipelines for drinking water transport and distribution network in small to medium cities: a case from Betanzos, Spain. Journal of Cleaner Production. 588-598.

Simonen, K. (2014). Life cycle assessment. Pocket architecture: Technical design series. Routledge.

Site web of International Energy Statistics (IES). https://www.eia.gov/beta/international/data/brows er/\#/?pa=0000000010000000000000000000000000000000000000000000000000u\&c=ruvvvvvfvt vnvv1 urvvvvfvvvvvvfvvvou20evvvvvvvvvnvvuvo\&ct=0\&vs=INTL.44-2-BLR-QBTU.A\&ord= $\mathrm{CR} \& \mathrm{vo}=0 \& \mathrm{v}=\mathrm{H} \&$ end $=2016$

Soskolne, C. L., Pagano, G., Cipollaro, M., Beaumont, J., \& Giordano, G. (1989). Epidemiologic and toxicologic evidence for chronic health effects and the underlying biologic mechanisms involved in sub-lethal exposures to acidic pollutants. Archives of Environmental Health, 44(3), 180-191.

Staff, A. C., Redman, C. W. G., Williams, D. R., et al. (2016). Pregnancy and long-term maternal cardiovascular health: Progress through harmonization of research cohorts and biobanks. Hypertension, 67, 251-260.

Teller, J., Marique, A. F., Loiseau, V., Godard, F., \& Delbar, C. (2014). Référentiel quartiers durables (Guides méthodologiques), Namur, Belgique, SPW, DGO4

Tsuo, Y. S., Wang, T. H., \& Ciszek, T. F. (1999) Crystalline-silicon solar cells for the 21st Century. National Renewable Energy Lab. 
US Census Bureau. Geographic terms and concepts-census tract. https://www.census.gov/geo/reference/ gtc/gtc_ct.html. Accessed March 26, 2019.

U.S. Dept. of Energy "Photovoltaic basics." Retrieved January 5, 2010, from http://www1.eere.energy. gov/solar/pv_basics.html.

U.S. Dept Valley Toxics Coalition (2009). Toward a just and sustainable solar energy industry. http://www. svtc.org/site/DocServer/Silicon_Valley_Toxics_Coalition_-_Toward_a_Just_and_Sust.pdf?docID= 821

USEPA (US Environmental Protection Agency) (1996). Air quality criteria for particulate matter. EPA/600/ P-95/001cF, Washington DC, USEPA

Van Marken Lichtenbelt, W. D., Vanhommerig, J. W., Smulders, N. M., Drossaerts, M. A. F. L., Kemerink, G. J., Bouvy, N. D., Schrauwen, P., \& Teule, G. J. J. (2009). Cold-activated brown adipose tissue in healthy adult men. New England Journal of Medicine, 360, 1500-1508. https://doi.org/10.1056/ NEJMoa0808718

WHO (2009). Guidelines for Indoor air quality: Dampness and mould. World Health Organization, Regional Office for Europe, Copenhagen.

WH (2012). Disability-adjusted life years (DALYs). Retrieved September 18, 2021, from https://www.who. int/data/gho/indicator-metadata-registry/imr-details/158.

Winkleby, M. A., Cubbin, C., \& Ahn, D. (2006). Effect of cross-level interaction between individual and neighborhood socioeconomic status on adult mortality rates. American Journal of Public Health, 96, 2145-2153.

Zhang, Y. T., Laraia, B. A., Mujahid, M. S., et al. (2015). Does food vendor density mediate the association between neighborhood deprivation and BMI? Epidemiology, 26, 344-352.

Publisher's Note Springer Nature remains neutral with regard to jurisdictional claims in published maps and institutional affiliations.

\section{Authors and Affiliations}

\section{Modeste Kameni Nematchoua ${ }^{1,2,3} \cdot$ Somayeh Asadi ${ }^{3} \cdot$ Esther Obonyo $^{4} \cdot$ Sigrid Reiter $^{2}$}

1 Beneficiary of an AXA Research Fund Postdoctoral Grant, Research Leaders Fellowships, AXA SA, 25 avenue Matignon, 75008 Paris, France

2 LEMA, ArGEnCo Department, University of Liège, Liège, Belgium

3 Department of Architectural Engineering, Pennsylvania State University, University Park, PA, USA

4 School of Engineering Design and Architectural Engineering, College of Engineering, Pennsylvania State University, University Park, PA 16802, USA 